\title{
Macromolecular absorption and cows' milk allergy
}

\author{
P Juvonen, I Jakobsson, T Lindberg
}

\begin{abstract}
The absorption of macromolecules was analysed by measuring serum concentrations of human $\alpha$-lactalbumin after feeding human milk, using a competitive radioimmunoassay. The control group consisted of 78 children fed by cows' milk formula; concentrations of $\alpha$ lactalbumin in their serum were low. The median concentrations in the different age groups varied between 7-13 $\mu \mathrm{g} \alpha$-lactalbumin/ 1 serum/1 human milk/kg body weight. Twenty eight children with cows' milk allergy were studied before introduction of a diet free of cows' milk. Nineteen had gastrointestinal and nine skin symptoms. High serum $\alpha$ lactalbumin concentrations were found. Only two children had $\alpha$-lactalbumin concentrations below $100 \mu \mathrm{g} \alpha$-lactalbumin/1 serum/1 human milk/kg body weight. Altogether 76 children on a diet free of cows' milk were studied directly after a cows' milk challenge; 26 developed symptoms. They had significantly higher serum $\alpha$-lactalbumin values than the 50 children with no symptoms upon challenge. Eighteen of the 26 children with symptoms had serum $\alpha$-lactalbumin concentrations of more than $100 \mu \mathrm{g} / 1$ serum/1 human milk/kg body weight in contrast with two of the 50 with no symptoms. Total serum IgE antibodies were analysed in 43 children. No correlation was found between concentrations of serum IgE and serum $\alpha$-lactalbumin in the children with cows' milk allergy.
\end{abstract}

It is generally accepted that antigenic macromolecules can penetrate the small intestinal mucosal membranes in quantities that may be of immunological importance. ${ }^{12}$ This transfer is more pronounced at an early age and even more pronounced in preterm infants. ${ }^{3}$ It is tempting to speculate that the increased absorption of macromolecules in neonates is a natural phenomenon leading to a state of tolerance to common food antigens. Studies in animals indicate that it is easier to induce immune tolerance in younger animals given dietary antigen from birth. ${ }^{45}$

It has been reported that patients with allergic diseases have an increased permeability to macromolecules through the small intestinal mucosa. ${ }^{167}$ It is possible that an increased absorption of macromolecules may be a part of the atopic constitution. It is also possible that an allergic reaction to food antigens may itself lead to an increased macromolecular absorption.

Methods of studying the permeability of the human intestine are based on determinations of marker molecules either in blood or urine. A number of marker proteins have been used such as bovine serum albumin, ovalbumin, cows' milk proteins, and horseradish peroxidase. Inert molecules like polyethylene glycols or polyvinyl pyrolidone have also been used as well as different carbohydrates. Synthetic polymers like polyethylene glycol molecules have a low molecular weight range from 200-2000, which is considerably smaller than most biologically important macromolecules. Besides, the transfer of these substances through the gut does not parallel the transfer of food proteins. ${ }^{8}$

When studying macromolecular absorption in humans with food allergy it seems most logical to use a protein molecule as a marker. When heterologous proteins, like cows' milk proteins, are used as markers local intestinal and systemic immune responses must be considered. This can be avoided by using a human protein as a marker of macromolecular absorption thereby achieving a more reliable measure of gut protein transfer.

In our studies we chose human $\alpha$-lactalbumin (molecular weight 14000 ), which is the dominant whey protein of human milk, as a marker of macromolecular absorption. ${ }^{9}$

The aim of this study was to determine whether absorption of human $\alpha$-lactalbumin was increased in children with suspected cows' milk allergy, before elimination of cows' milk, and after a cows' milk challenge.

Patients and methods

A total of 78 children fed on cows' milk formula acted as controls; there were 38 girls and $\mathbf{4 0}$ boys. They were either healthy children at the child health unit or patients at outpatient clinics who did not have an allergy or gastrointestinal problems.

There were two groups of patients. The first group consisted of 28 children with cows' milk allergy who were studied before introduction of a cows' milk free diet (13 girls and 15 boys). The children were divided in two groups according to their symptoms. Nineteen children had gastrointestinal symptoms (diarrhoea, vomiting, abdominal pain, failure to gain weight) and nine had skin symptoms (urticaria, eczema). All became symptom free and gained weight when treated with a strict diet free of cows' milk; 15 children received soya formula (SojaSemp, Semper), and 13 casein hydrolysate formula (Nutramigen, Bristol-Myers). In all these children the symptoms vanished on a diet free of cows' milk and returned after challenge with cows' milk.

The second group consisted of 76 children 
(40 girls and 36 boys) being treated with a cows' milk free diet: 44 children received SojaSemp and 32 Nutramigen. They were studied immediately after a challenge with cows' milk. The children were divided in two groups according to their symptoms. Fifty two had gastrointestinal symptoms and 24 had skin symptoms. Increasing amounts of cows' milk (1 ml$100 \mathrm{ml}$ ) were given during one day. Twenty six children developed symptoms on the challenge and 50 children did not.

All the children were divided into four groups according to age: 2-6 months, 6-12 months, 12-24 months, and older than 24 months.

Capillary blood samples were taken 30 and 60 minutes after intake of preheated $\left(63^{\circ} \mathrm{C}, 30\right.$ minutes) human milk from our milk bank. Infants 2-6 months of age received $30 \mathrm{ml} / \mathrm{kg}$ body weight and infants above 6 months of age received $20 \mathrm{ml} / \mathrm{kg}$ body weight with a maximum of $200 \mathrm{ml}$.

Total serum IgE was analysed according to Kjellman et $a l^{10}$ in 43 children and specific cows' milk IgE in serum from eight children. ${ }^{10}$

A competitive radioimmunoassay was used to measure concentrations of $\alpha$-lactalbumin in serum. ${ }^{9}$ No interspecies antigenic cross reactivity of human $\alpha$-lactalbumin against bovine $\alpha$ lactalbumin has been shown with the Ouchterlony technique, and infants fed cows' milk had no measurable amounts of human $\alpha$ lactalbumin in serum. ${ }^{9}$ Results were expressed as $\mu \mathrm{g} \alpha$-lactalbumin $/ 1$ serum $/ 1$ given human milk/kg body weight. The detection limit for the radioimmunoassay was $10 \mu \mathrm{g} / \mathrm{l}$ serum. Peak values (at 30 or 60 minutes) were used.

The study was approved by the ethical committee, University of Lund.

Data were analysed by the Mann-Whitney U test.

Results

The serum $\alpha$-lactalbumin concentrations in the control children were low, and median concentrations in the different age groups were between 7-13 $\mu \mathrm{g} \alpha$-lactalbumin/1 serum/1 human milk/kg body weight (fig 1 ).

In 28 children allergic to cows' milk before the introduction of a cows' milk free diet high

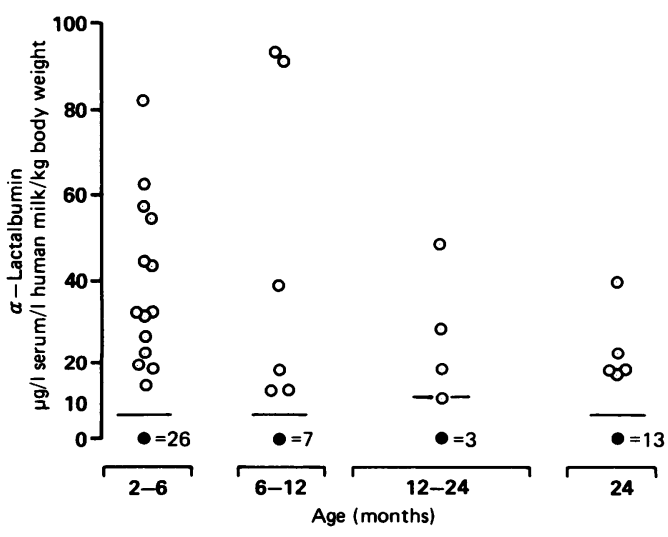

Figure 1 Serum concentrations of human $\alpha$-lactalbumin after a human milk feed in 78 control children of different ages fed on cows' milk formula. Solid circles denote children with undetectable concentrations of $\alpha$-lactalbumin; the solid line shows median concentrations. serum concentrations of $\alpha$-lactalbumin were found (fig 2). Only two children in this group had $\alpha$-lactalbumin below $100 \mu \mathrm{g} / 1$ serum/1 human milk/kg body weight. The total serum IgE values were analysed in 21 children. The children with high total IgE $(n=10)$ had a median serum $\alpha$-lactalbumin concentration of $146 \mu \mathrm{g} / \mathrm{l}$. The children with normal serum IgE values $(n=11)$ had a median concentration of $150 \mu \mathrm{g} / \mathrm{l}$. Cows' milk IgE antibodies were analysed in serum from three children. ${ }^{10}$ In two of these children cows' milk IgE antibodies were found in serum. In both the serum $\alpha$ lactalbumin concentrations were high (197 and $926 \mu \mathrm{g} / \mathrm{l})$. The third child, however, who had no detectable cows' milk IgE antibodies, also had a high serum $\alpha$-lactalbumin $(625 \mu \mathrm{g} / \mathrm{l})$.

Figure 3 shows the results from the 76 children who were studied immediately after a challenge with cows' milk. All were on a cows' milk free diet. The children who had a clinical reaction to the cows' milk challenge $(n=26)$ had higher serum concentrations of $\alpha$-lactalbumin than those who did not react to the challenge $(n=50)$. Eighteen out of 26 children with symptoms had serum $\alpha$-lactalbumin concentrations above $100 \mu \mathrm{g} / 1$ serum/1 human milk/kg body

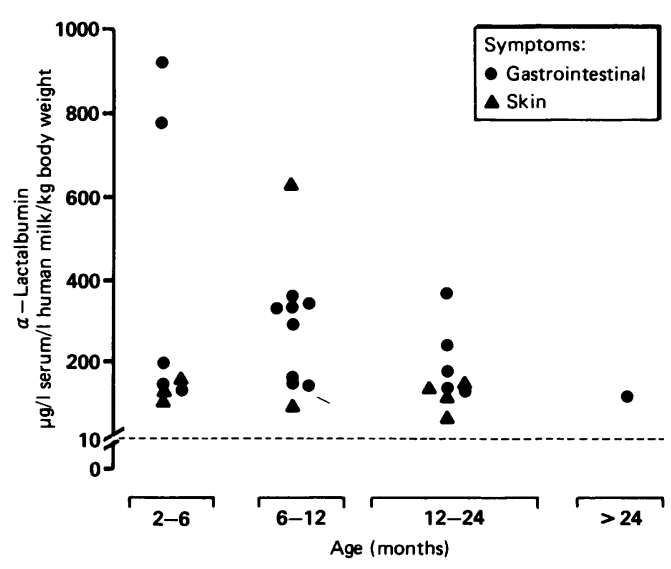

Figure 2 Serum concentrations of human $\alpha$-lactalbumin after a human milk feed in 28 children with cows' milk allergy before introduction of cows' milk free diet.

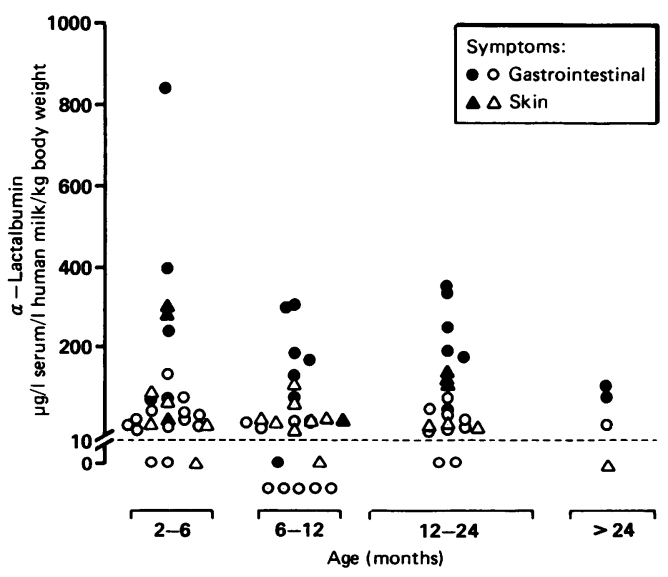

Figure 3 Serum concentration of human $\alpha$-lactalbumin after a human milk feed directly after a challenge with cows' milk in 76 children suspected of cows' milk allergy. All the children were on a cows' milk free diet. The open symbols denote the symptoms in the children who did not react to the challenge $(n=50)$; the solid symbols denote the symptoms of those who did $(n=26)$. 

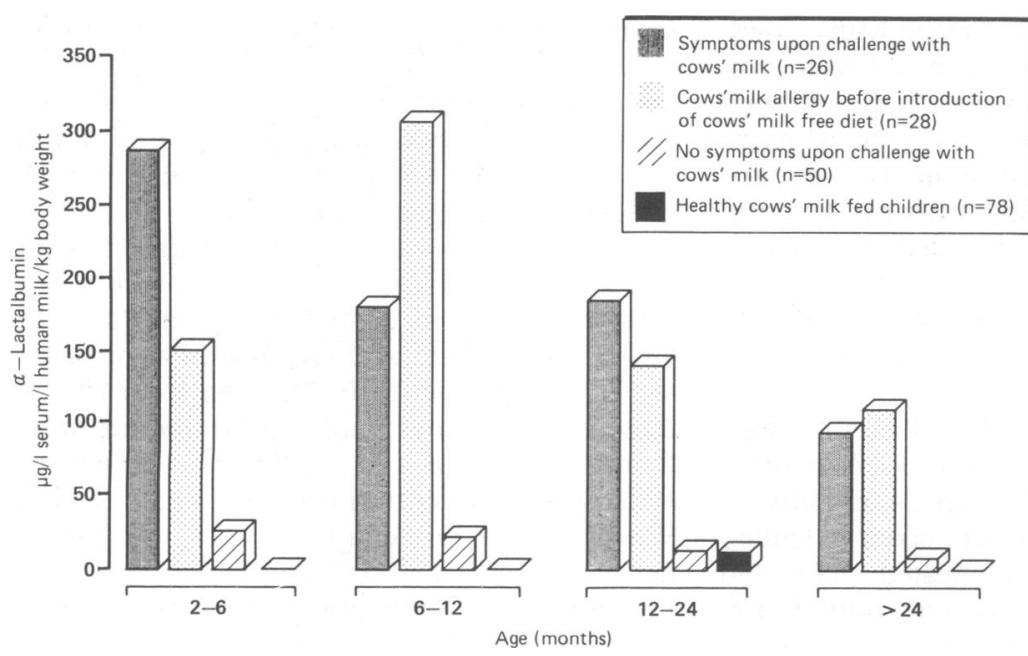

Figure 4 Serum content of human $\alpha$-lactalbumin (median values) after a human milk feed in all four study groups. trointestinal symptoms. Small intestinal mucosal damage caused by the allergic reaction could have been one reason for the increased absorption of $\alpha$-lactalbumin.

Alternatively increased gut absorption of macromolecules may be present in all individuals predisposed to allergy. We were unable to find any correlation between serum IgE and serum $\alpha$-lactalbumin concentrations in the children with cows' milk allergy. Many children with cows' milk allergy, however, do not have an IgE mediated allergy but a cell mediated immune reaction giving rise to an increase in gut intraepithelial lymphocyte counts and to various degrees of villous atrophy. ${ }^{11} 12$

There are, as far as we know, no earlier studies on the macromolecular absorption of homologous protein in food allgery. Results from studies using heterologous proteins are difficult to compare with ours as they are influenced by the local and systemic immunological reactions in the patients. Dannaeus et al studied 42 children with coeliac disease on food to determine the uptake of ovalbumin in serum after a test meal. ${ }^{13}$ The concentrations of ovalbumin were lower in the children with high antibody values then in those with low values. The antigen concentrations were reported to be significantly lowered after treatment with sodium cromoglycate in six patients. Paganelli and coworkers demonstrated the presence of $\beta$ lactoglobulin as well as ovalbumin in a complexed form after a test meal in patients with atopic eczema as well as in normals. ${ }^{14}$ Children allergic to cows' milk were reported to have IgA, IgG, $\mathrm{IgE}$, and $\mathrm{C}_{\mathrm{lq}}$ containing complexes as well as ovalbumin and $\beta$-lactoglobulin containing complexes after a cows' milk challenge, whereas healthy controls mostly had IgA and $\beta$ lactoglobulin containing complexes after a similar challenge. ${ }^{15}$

Our results suggesting increased absorption of protein molecules in the gut are in contrast to findings from studies using low molecular weight markers. ${ }^{716}$ Du Mont et al studied gastrointestinal permeability in 18 atopic eczematous children compared with 10 control children using sugar mixtures of L-rhamnose and lactulose. ${ }^{17} \mathrm{~A}$ significant difference in gastrointestinal permeability was not demonstrated between atopic and control children. FälthMagnusson et al studied gastrointestinal permeability in allergic and healthy children after treatment with sodium cromoglycate using polyethylene glycol molecules (molecular weight $400-1000){ }^{7}$ There were no significant differences in the first test using polyethylene glycol between healthy and allergic children. However, after treatment with sodium cromoglycate the uptake was significantly lower in allergic children. Jackson et al using polyethylene glycols with higher molecular weights found that the absorption of large molecules (molecular weight 4000) was increased in all patients with eczema regardless of the presence of food allergy. ${ }^{18}$ This was consistent with increased antigen absorption in atopic disease.

The present study has shown an increased absorption of human $\alpha$-lactalbumin in children reacting to the cows' milk challenge. This could concentrations were increased whether the children presented with intestinal or skin symptoms. The highest serum values of $\alpha$ lactalbumin were found in children with gas- 
be explained in two ways: firstly, the jejunal mucosa in infants with cows' milk allergy could be damaged after exposure to cows' milk, allowing absorption of relatively large amounts of macromolecules. Secondly, an increased macromolecular absorption may be seen in these children even when free of symptoms during a cows' milk free diet.

Savilahti studied the intestinal mucosa after a milk challange. ${ }^{19} \mathrm{He}$ showed that at the time of clinical relapse there was a two to four times increase in the numbers of IgA and IgM containing cells in the jejunal mucosa. He suggested that cows' milk was the agent responsible for this local intestinal reaction, which coincided with the development of clinical symptoms. Further longitudinal prospective studies are needed including the repeated analyses of human $\alpha$-lactalbumin absorption, to elucidate whether increased macromolecular absorption is part of an allergic constitution. Further studies are also necessary to determine whether absorption of human $\alpha$-lactalbumin can be used as an objective method to measure the reaction to cows' milk after a cows' milk challenge.

In conclusion it has been found that increased absorption of proteins as measured by serum content of human $\alpha$-lactalbumin occurs in children with cows' milk allergy. Whether the increased macromolecular absorption is a part of an allergic constitution or results from mucosal damage remains to be elucidated.

1 Walker WA, Isselbacher KJ. Uptake and transport of macromolecules by the intestine: possible role in clinical disorders. Gastroenterology 1974;67:531-50.

2 Walker WA. Intestinal transport of macromolecules. In: Johnson LR. Physiology of the gastrointestinal tract. New York: Raven Press, 1981:1271-89.
3 Axelsson I, Jakobsson I, Lindberg T, et al. Macromolecular absorption in preterm and term infants. Acta Paediat Scand 1989;78:532-37.

4 Pathirana C, Goulding N, Gibney MJ, et al. Immune tolerance produced by pre- and postnatal exposure to dietary ance produced by pre- and postnatal exposure to dietary

5 Telemo E, Jakobsson I, Weström BR, et al. Maternal dietary antigens and the immune response of the offspring in the antigens and the immune response of the

6 Walker-Smith JA, Ford RPK, Phillips AD. The spectrum of gastrointestinal allergies to food. Ann Allergy 1984;53: 629-36.

7 Fälth-Magnusson K, Kjellman NIM, Magnusson KE, Sundqvist $\mathrm{T}$. Intestinal permeability in healthy and allergic children before and after sodium-chromoglycate treatmen assessed with different sized polyethylenglucols (PEG 400 and PEG 1000). Clin Allergy 1984;14:277-86.

8 Weström BR, Svendsen J, Ohlsson BG, et al. Intestinal transmission of macromolecules (BSA and FITC-labelled dextrans) in the neonatal pig. Influence of age of piglet and molecular weight of markers. Biol Neonate $1984 ; 46: 20-6$.

9 Jakobsson I, Lindberg $T$ Lothe $L$, al. Human $\alpha$ lactalbumin as a marker of macromolecular absorption. Gut 1986;27:1029-34.

$10 \mathrm{Kjellman}$ NM, Johansson SGO, Roth A. Serum IgE-levels in healthy children quantified by a sandwich technique healthy children quantified by

11 Axelsson I, Jakobsson I, Lindberg T. Macromolecular absorption in preterm and term infants. Acta Paediatr absorption in preterm

12 Ferguson A. Models of immunologically-driven small intestinal damage. In: Marsh N, ed. Immunopathology of the smal intestine. Chichester: John Wiley, 1987:225-52.

13 Walker-Smith JA. Cows' milk intolerance as a cause of postenteritis diarrhoea. $\mathcal{F}$ Pediatr Gastroenterol Nutr 1982;1: 163-73.

14 Dannaeus A, Inganäs M, Johansson SGO, Foucard T. Intestinal uptake of ovalbumin in malabsorption and food allergy in relation to serum IgG antibody and orally administered sodium cromolycate. Clin Allergy 1979;9:263-70.

15 Paganelli R Levinsky RJ Atherton DJ. Detection of specific antigen within circulating immune complexes: validation of antigen within circulating immune complexes: validation of plexes formed in healthy and food-allergic subjects. Clin plexes formed in healthy and

16 Paganelli R, Atherton DJ, Levinsky RJ. Differences between normal and milk allergic subjects in their immune normal and milk allergic subjects in their immune responses $201-6$.

17 Du Mont GCL, Bead RD, Menziesis IS. Gastrointestinal permeability in food allergy and eczema. Clin Allergy 1984;14 55-9.

18 Jackson PG, Lessof MH, Baker RWR, Ferret J, Macdonald DM. Intestinal permeability in patients with eczema and food allergy. Lancet 1981;i:1285-6.

19 Savilahti E. Immunochemical study of the malabsorption syndrome with cows' milk intolerance. Gut 1973;14: 491-501. 